\title{
Flooding and Oil Spill Disaster Relief using Sentinel of Remote Sensing Satellite Data
}

\author{
Kohei Arai \\ Faculty of Science and Engineering \\ Saga University, Saga City \\ Japan
}

\begin{abstract}
Flooding and oil spill disaster relief using Sentinel of remote sensing satellite data is conducted. Kyushu, Japan had severe heavy rain from 26 August to 30 August 2019. Optical sensor and Synthetic Aperture Radar: SAR onboard remote sensing satellite is used for disaster relief. NDVI and SWIR data derived from the Sentinel data are used for disaster relief. Merits and demerits of the optical sensor and SAR instrument are compared from the disaster relief of point of view.
\end{abstract}

Keywords-Sentinel; disaster relief; satellite remote sensing; flooding; oil spill; synthetic aperture radar; optical sensor; vegetation index

\section{INTRODUCTION}

On the morning of August 26, the front line near the southern part of Kyushu moved northward to the vicinity of the Tsushima Strait on the 27th day. For this reason, it was a record heavy rain in Saga Prefecture. About record short-term heavy rain (analytical rainfall) from 04:00 to 04:50 on the 28th, Taku City, Takeo City, Ogi City, Kohoku Town, Saga City, Omachi Town, Shiraishi Town, Kanzaki City, Yoshinogari Town It was analyzed from about $110 \mathrm{~mm}$ to over $120 \mathrm{~mm}$ per hour in the vicinity. Due to the heavy rain, landslide and oil spill disaster is occurred. Such disaster can be relieved from space, spaceborne mission instrument data.

There are many kinds of mission instruments onboard remote sensing satellites. Typical instruments of passive type are optical sensors, visible to near infrared radiometer, shortwave infrared radiometers, thermal infrared radiometers and microwave radiometers while those of active instruments, Synthetic Aperture Radar: SAR. Both types of mission instruments have merits and demerits for disaster relief. It would be desirable to use both mission instrument data considering their merits and demerits.

Typically, SAR data can be used under all-weather condition, day and night as well as cloudy and rainy conditions. On the other hand, optical sensors do not work under the conditions, night time, and cloudy and rainy conditions. Physical quantities derived from these mission instruments are also different from each other. Essentially, SAR data reflect surface slope, roughness, soil moisture, and so on. Meanwhile, SWIR data, moisture index, vegetation index, land cover types etc. can be derived from the optical sensors. Therefore, depending on the purposes, both instrument data can be used separately or collaboratively.
In order to conduct disaster relief of flooding area detection and oil spill area detection, Sentinel-1 of SAR data and Sentinel-2 of optical sensor data are used collaboratively in this research. Results show effectiveness and efficient usage of SAR and optical sensor data for landslide and oil spill disaster relief.

The next section describes related research works followed by the research background of this study. Then, experimental results are described followed by conclusions together with some discussions.

\section{RELATED RESRACH WORKS}

There are some related studies on disaster relief and mitigation research works, method for estimation of damage grade and damaged paddy field areas due to salt containing sea breeze with typhoon using remote sensing imagery data is proposed and validated [1]. Back-up communication routing through Internet satellite WINDS for transmitting of disaster relief data are also proposed [2]. On the other hand, cellular automata for traffic modeling and simulation in a situation of evacuation from disaster areas are proposed [3]. Meanwhile, micro traffic simulation with unpredictable disturbance based on Monte Carlo simulation: effectiveness of the proposed agent cars of Sidoarjo hot mudflow disaster is discussed [4] while probabilistic cellular automata based approach for prediction of hot mudflow disaster area and volume is proposed and validated [5]. In the meantime, two dimensional CA approach for disaster spreading is proposed [6]. Micro traffic simulation with unpredictable disturbance based on Monte Carlo simulation and effectiveness of the proposed agent cars of Sidoarjo hot mudflow disaster is discussed already [7].

Probabilistic cellular automata based approach for prediction of hot mudflow disaster area and volume is reviewed and re-evaluated [8] together with new approach of prediction of Sidoarjo hot mudflow disaster area based on probabilistic Cellular Automata: CA [9]. Cellular automata for traffic modeling and simulation in a situation of evacuation from disaster areas -Cellular Automata Simplicity behind Complexity- is discussed [10].

Sensor network for landslide monitoring with laser ranging system avoiding rainfall influence on laser ranging by means of time diversity and satellite imagery data based landslide disaster relief is proposed and validated [11]. Task allocation model for rescue disable persons in disaster area with help of 
volunteers is also proposed [12]. Deceleration in the evacuation from disaster area is discussed [13]. Cell based GIS as cellular automata for disaster spreading predictions and required data systems are proposed and validated already [14]. On the other hand, visualization of 5D assimilation data for meteorological forecasting and its related disaster mitigation utilizing VIS5D of software tool is proposed and well reported [15].

Meanwhile, vital sign and location/attitude monitoring with sensor networks for the proposed rescue system for disabled and elderly persons who need a help in evacuation from disaster areas is proposed and validated [16] together with method and system for human action detection with acceleration sensors for the proposed rescue system for disabled and elderly persons who need a help in evacuation from disaster areas [17]. Vital sign and location/attitude monitoring with sensor networks for the proposed rescue system for disabled and elderly persons who need a help in evacuation from disaster areas is discussed and re-evaluated [18].

Method and system for human action detection with acceleration sensors for the proposed rescue system for disabled and elderly persons who need a help in evacuation from disaster areas is proposed and well validated [19], [20].

\section{RESEARCH BACKGROUND}

On the morning of August 26, the front line near the southern part of Kyushu moved northward to the vicinity of the Tsushima Strait on the 27th day. For this reason, it was a record heavy rain in Saga Prefecture. Saga prefecture is situated in the north portion of Kyushu, Japan as illustrated in Fig. 1 .

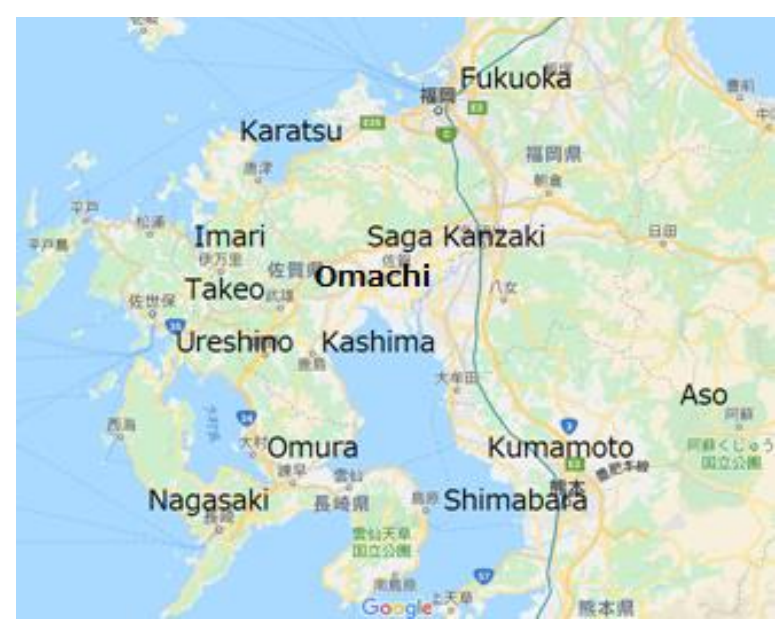

Fig. 1. Location of Saga Prefecture.

Fig. 2 shows MTSAT (Japanese Meteorological Satellite in the geostationary orbit) imagery data acquired (a) at 3 a.m. on August 262019 and (b) at 21:00 on August 30 2019, respectively. During from 26 to 30 August 2019, heavy rain was continued recursively. The heaviest rainfall was observed in the morning on 28 August 2019 as shown in Fig. 3. Much greater than $100 \mathrm{~mm} /$ hour was recorded in the morning. Also, rainfall rate and accumulated rainfall measured during from 28 to 30 August 2019 is shown in Fig. 4. Accumulated rainfall reached to $500 \mathrm{~mm}$ while the peak rainfall rate reached to 100 $\mathrm{mm}$, respectively. As the results, landslide (collapsed) and oil spill were occurred in the Omachi-Town in Saga prefecture.
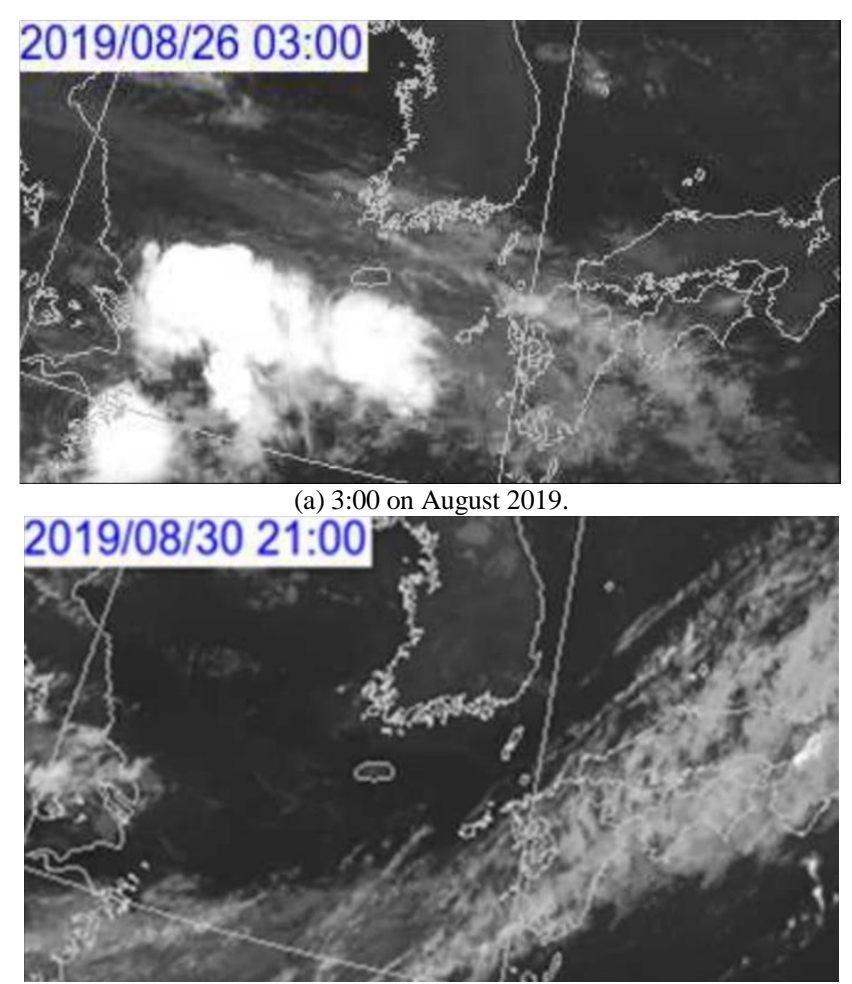

(b) 21:00 on August 2019

Fig. 2. MTSAT (Japanese Meteorological Satellite in the Geostationary Orbit) Imagery Data Acquired (a) at 3 a.m. on August 262019 and (b) at 21:00 on August 302019.

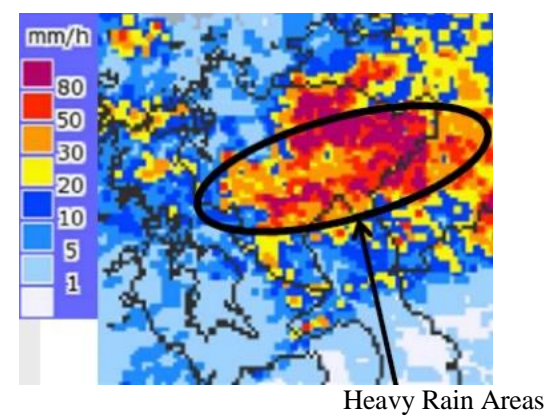

Fig. 3. Rain Radar Derived Rainfall Distribution which was Observed in the Morning on 28 August 2019.

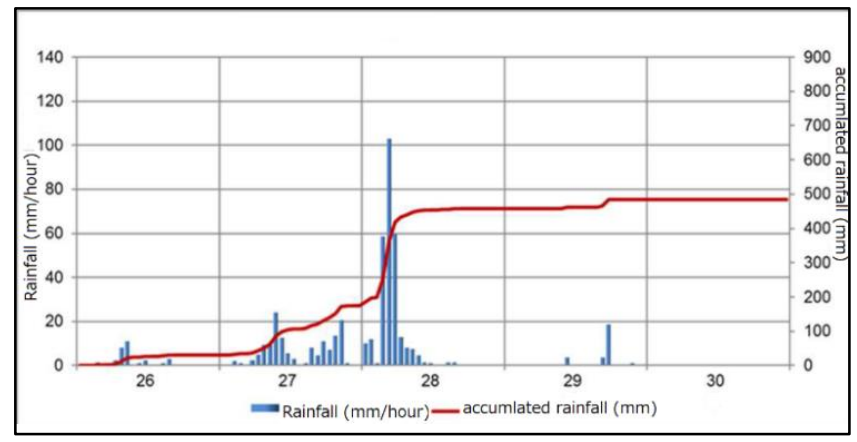

Fig. 4. Rainfall Rate and Accumulated Rainfall Measured During from 28 to 30 August 2019. 


\section{Disaster Relief With SATELLITE DATA}

\section{A. Intensive Study Area}

In the morning of 28th, "Botayama Wanpaku Park" in Omachi-Town, Saga Prefecture, was affected by heavy rain, and the slope collapsed about 50 meters wide and about 20 meters high, blocking the town road leading to the park. Fig. 5(a) shows photo of collapsed area while Fig. 5(b) shows photo of oil spill area in Omachi-Town. These disaster areas are situated in the Omachi-Town shown in Fig. 6.

The oil spill was occurred at the bottom left corner in Fig. 6(b) and (c) while the collapsing was happened at the top right corner in Fig. 6(b) and (c), respectively.

\section{B. Remote Sensing Satellite Data Analysis}

Sentinel-1 of SAR data is used for detection of oil spill and collapsed area detection. There are two Sentinel-1 satellite, 1A and $1 \mathrm{~B}$. Both of repetition cycle is 12 days. Therefore, it is possible to observe the earth surface every 6 days. Also, there are two polarization of available SAR data, VV and VH (V and $\mathrm{H}$ stands for vertical and horizontal polarization so that VV means emit V polarization of Electromagnetic Wave: EM ( $\mathrm{C}$ band) and receive $\mathrm{V}$ polarization of EM return echo from the earth surface. Spatial resolution of SAR on the ground is 5 $\mathrm{m}$. Table I shows major specification of Sentinel-1 of SAR.

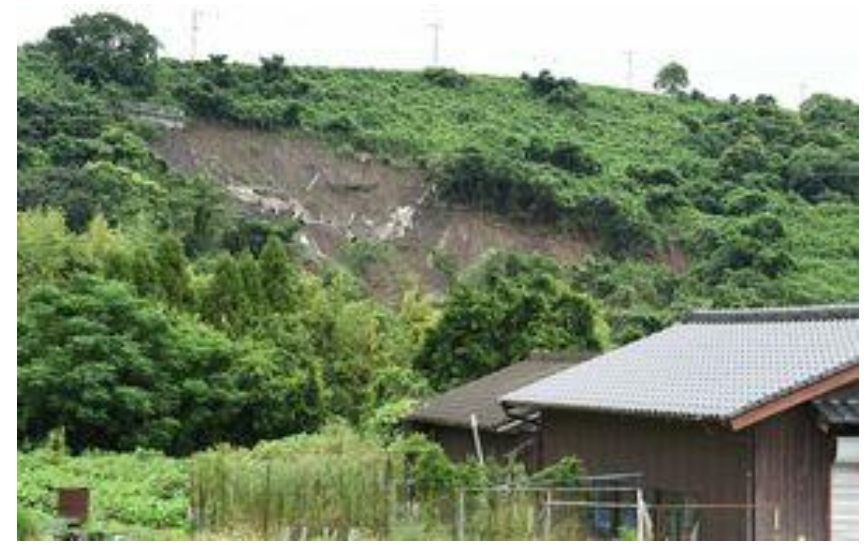

(a) Collapsed Area.

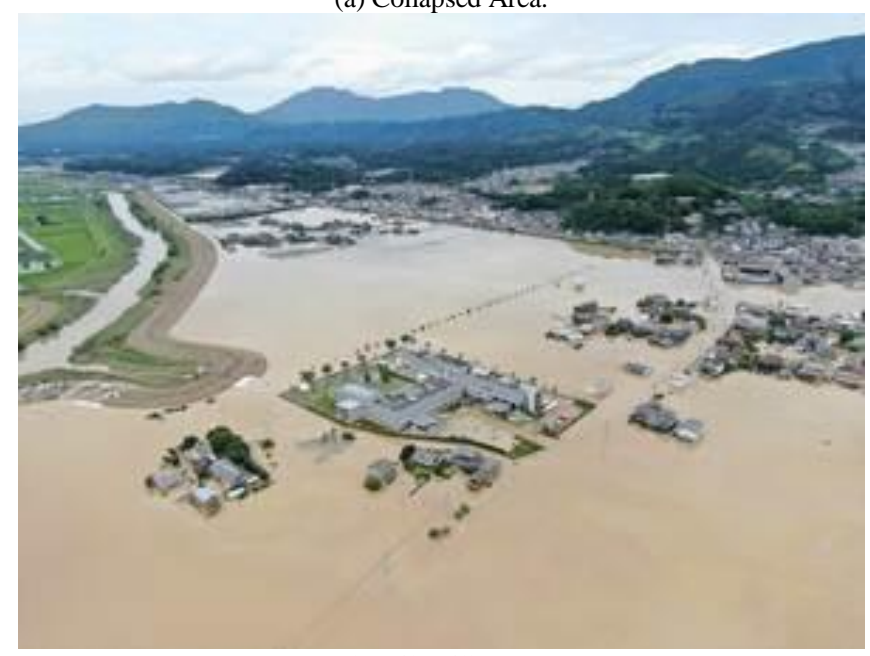

(b) Oil Spill Area.

Fig. 5. Photos of the Collapsed Area and Oil Spill Area Due to Heavy Rain.
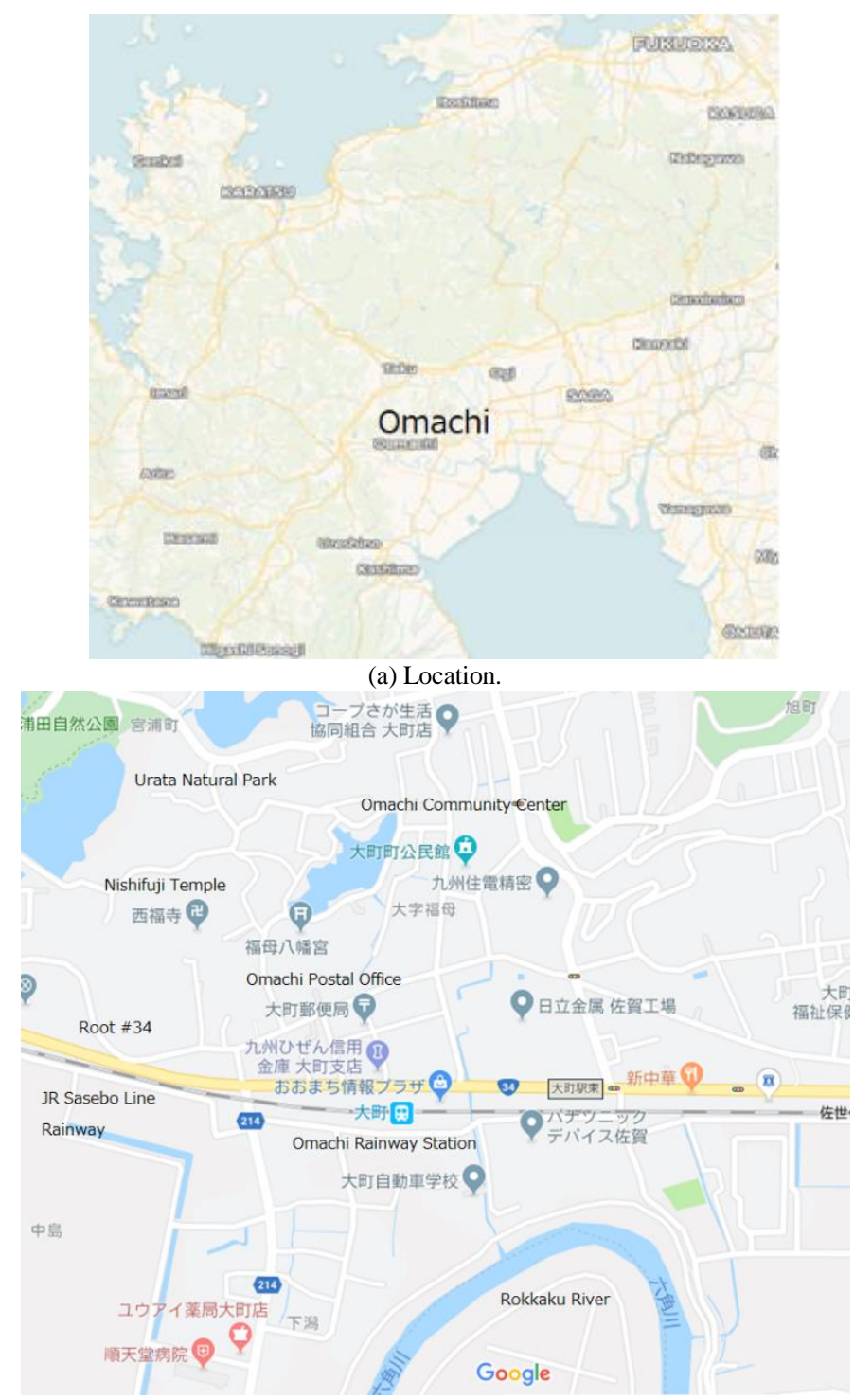

(b)Oil Spill and Collapsed Areas on Google Map.

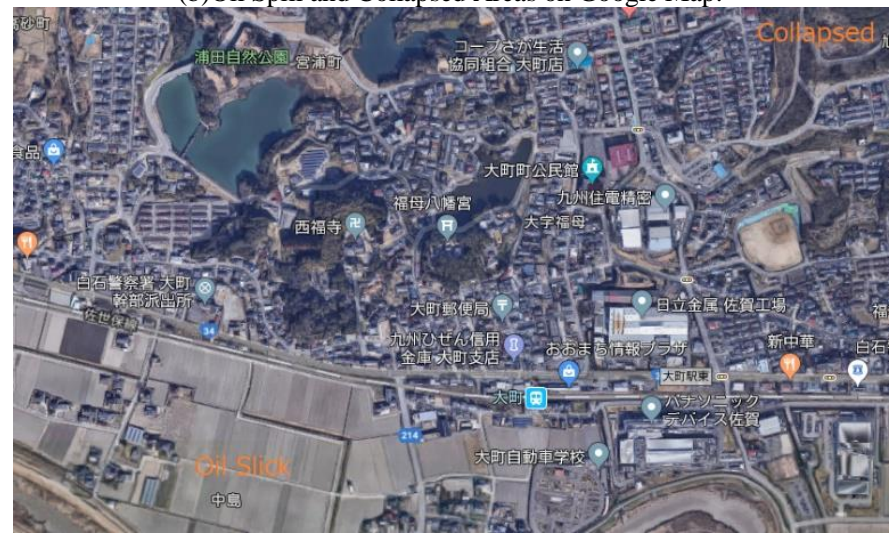

(c) Oil Spill and Collapsed Areas on Google Map.

Fig. 6. Intensive Study Areas of Omachi-Town, Saga Prefecture.

TABLE. I. MAJOR SPECIFICATION OF SENTINEL-1 OF SAR

\begin{tabular}{|l|l|l|l|}
\hline Stripmap & $80 \mathrm{~km}$ & $5 \mathrm{~m} \times 5 \mathrm{~m}$ & HH-HV, VV-VH \\
\hline
\end{tabular}


Fig. 7(a) shows topographic map of Omachi town while Fig. 7(b) shows ortho rectified VV sigma note (back scattered cross section of the earth surface) in unit of decibel of the areas of oil spill and collapsed acquired at 09:21 UTC on August 142019 (just before oil spill and collapse are occurred). Meanwhile, Fig. 7(c) shows same area of ortho rectified VH sigma note (back scattered cross section of the earth surface) in unit of decibel of the areas of oil spill and collapsed acquired at the same time.

Meanwhile, Sentinel-2 carries $10 \mathrm{~m}$ resolution of visible to short wave infrared radiometer. Table II shows major specification of optical sensor onboard Sentinel-2 Band 12 is Short Wave Infrared SWIR band while band 8 is Near Infrared: NIR band. Also, band 4 is red color band so that Normalized Deviation of Vegetation Index: NDVI and be retrieved with the following equation.

$\mathrm{NDVI}=(\mathrm{B} 8-\mathrm{B} 4) /(\mathrm{B} 8+\mathrm{B} 4)$

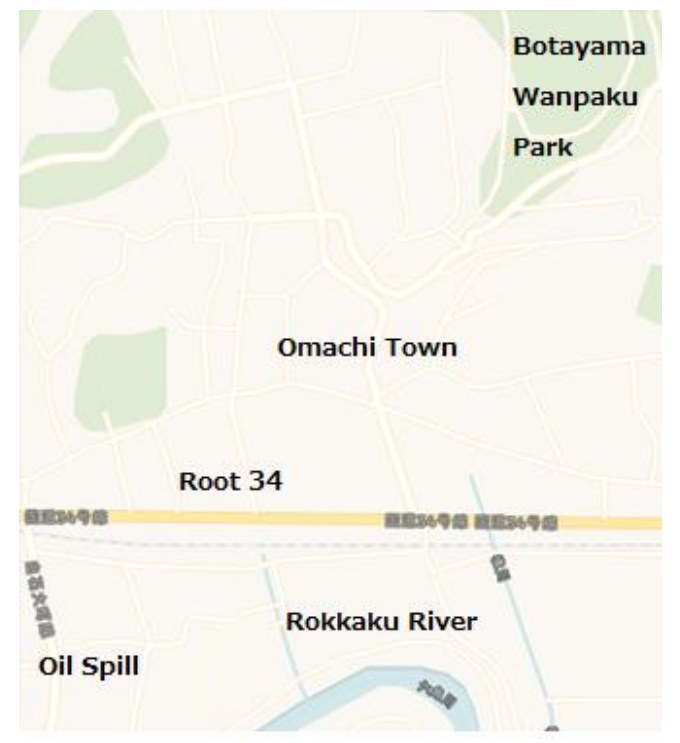

(a) Topographic Map.

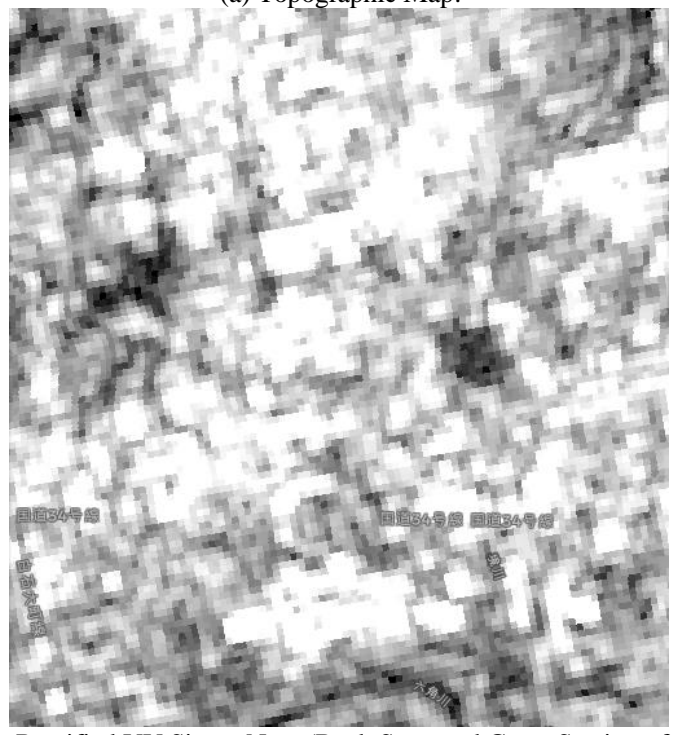

(b) Ortho Rectified VV Sigma Note (Back Scattered Cross Section of the Earth Surface) in unit of Decibel of the Areas of Oil Spill and Collapsed Acquired at 21;17 UTC on August 152019

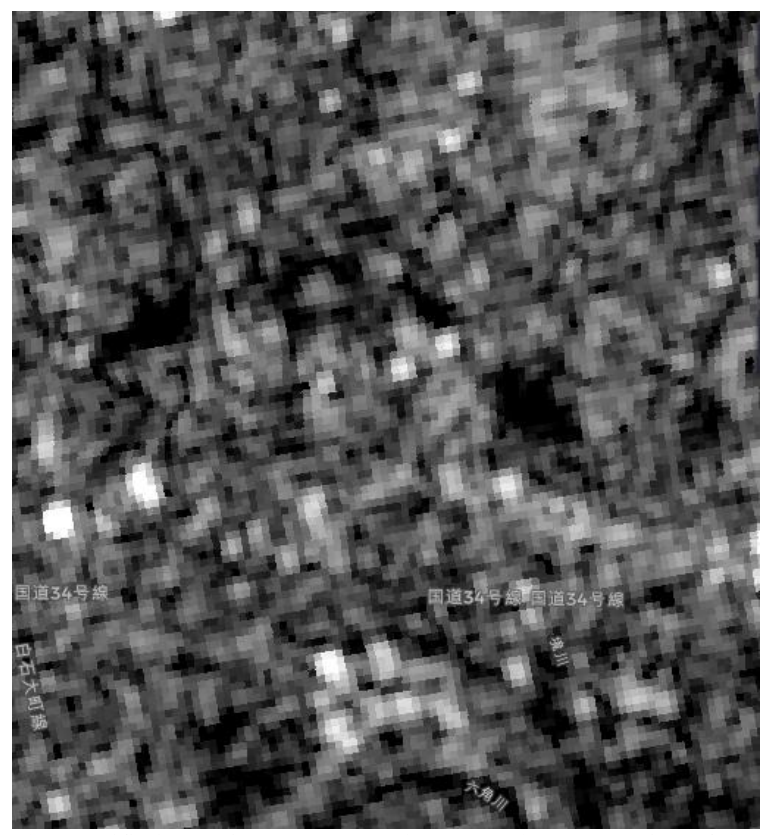

(c) Ortho Rectified VH Sigma Note (Back Scattered Cross Section of the Earth Surface) in unit of Decibel of the Areas of Oil Spill and Collapsed Acquired at the Same Time.

Fig. 7. Disaster Relief Result.

At the top right corner, Botayama Wanpaku park of collapsed area is situated while oil spill area is situated bottom left corner, respectively. On the other hand, Fig. 8(a) shows ortho rectified VV sigma note (back scattered cross section of the earth surface) in unit of decibel of the areas of oil spill and collapsed acquired at 09:22 UTC on September 12019 (just after oil spill and collapse are occurred). Meanwhile, Fig. 7(b) shows same area of ortho rectified VH sigma note (back scattered cross section of the earth surface) in unit of decibel of the areas of oil spill and collapsed acquired at the same time.

It is quite obvious that VV sigma note at the collapsed area acquired after the collapse is occurred is much higher than that of before the collapsing. Also, it is found that VV sigma note at the oil spill area acquired after the collapse is occurred is much lower than that of before the oil spill. These are almost same for the VH sigma note.

TABLE. II. MAJOR SPECIFICATION OF OPTICAL SENSOR ONBOARD SENTINEL-2

\begin{tabular}{|l|l|l|}
\hline B1 & $443 \mathrm{~nm}$ & $60 \mathrm{~m}$ \\
\hline B2 & $490 \mathrm{~nm}$ & $10 \mathrm{~m}$ \\
\hline B3 & $560 \mathrm{~nm}$ & $10 \mathrm{~m}$ \\
\hline B4 & $665 \mathrm{~nm}$ & $10 \mathrm{~m}$ \\
\hline B5 & $705 \mathrm{~nm}$ & $20 \mathrm{~m}$ \\
\hline B6 & $740 \mathrm{~nm}$ & $20 \mathrm{~m}$ \\
\hline B7 & $775 \mathrm{~nm}$ & $20 \mathrm{~m}$ \\
\hline B8 & $842 \mathrm{~nm}$ & $10 \mathrm{~m}$ \\
\hline B8a & $865 \mathrm{~nm}$ & $20 \mathrm{~m}$ \\
\hline B9 & $940 \mathrm{~nm}$ & $60 \mathrm{~m}$ \\
\hline B10 & $1375 \mathrm{~nm}$ & $60 \mathrm{~m}$ \\
\hline B11 & $1610 \mathrm{~nm}$ & $20 \mathrm{~m}$ \\
\hline B12 & $2190 \mathrm{~nm}$ & $20 \mathrm{~m}$ \\
\hline
\end{tabular}


Also, SWIR color composite image can be derived from Band 12, Band 8A and Band 4 while false color composite image can be derived from Band 8, 4, and 3 where Band 3 is green color band.

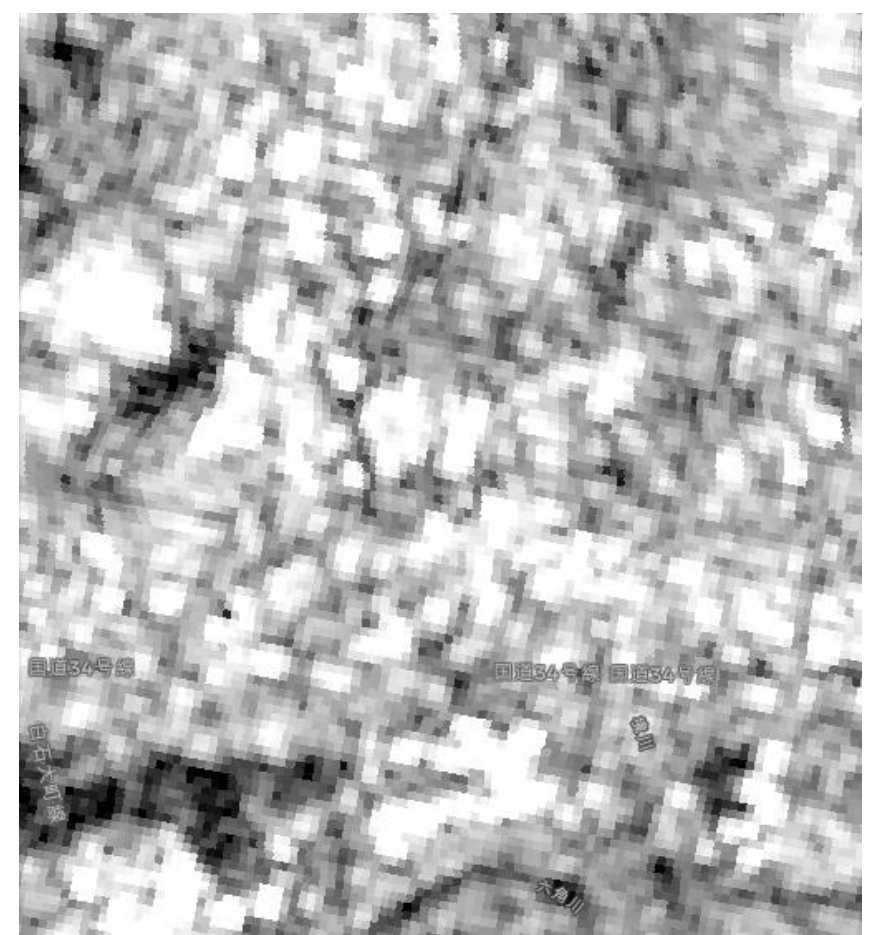

(a) Ortho Rectified VV Sigma Note (Back Scattered Cross Section of the Earth Surface) in unit of Decibel of the Areas of Oil Spill and Collapsed Acquired at 09:22 UTC on September 12019.

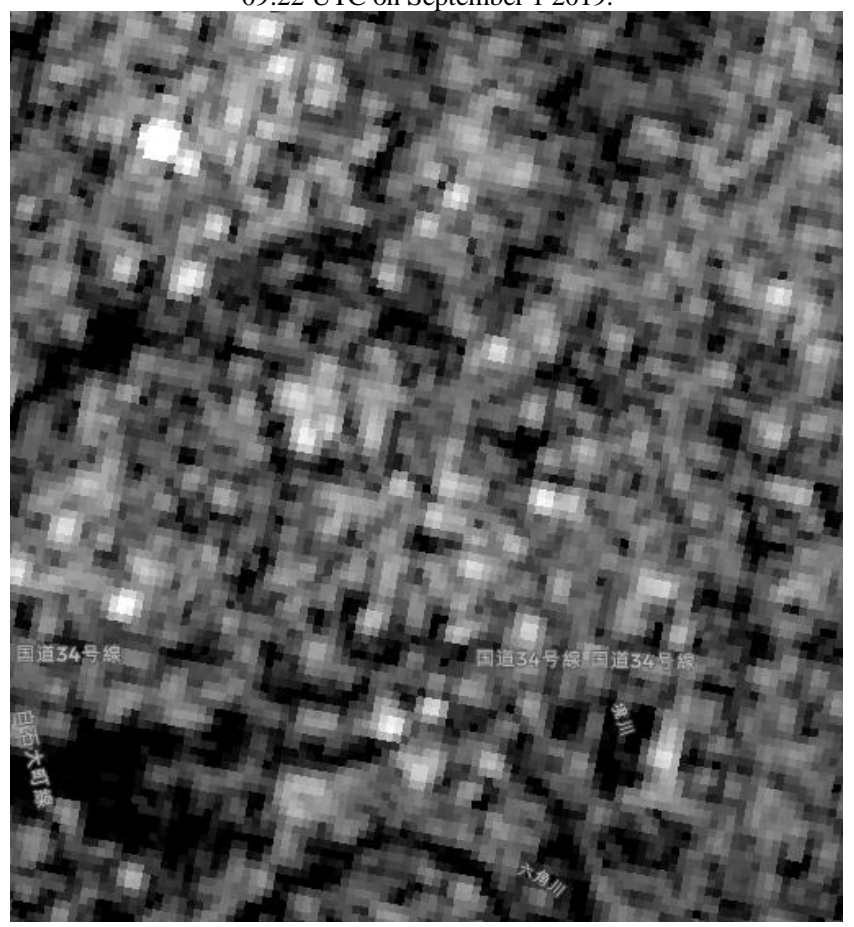

(b) Ortho Rectified VH Sigma Note (Back Scattered Cross Section of the Earth Surface) in unit of Decibel of the Areas of Oil Spill and Collapsed Acquired at the Same Time.

Fig. 8. Disaster Relief Result
Sentinel-2 data derived false color image which is acquired at 02:08 on August 132019 is shown in Fig. 9(a) while NDVI is shown in Fig. 9(b). Also, Fig. 9(c) shows SWIR color composite image. These imagery data are acquired just before the heavy rain.
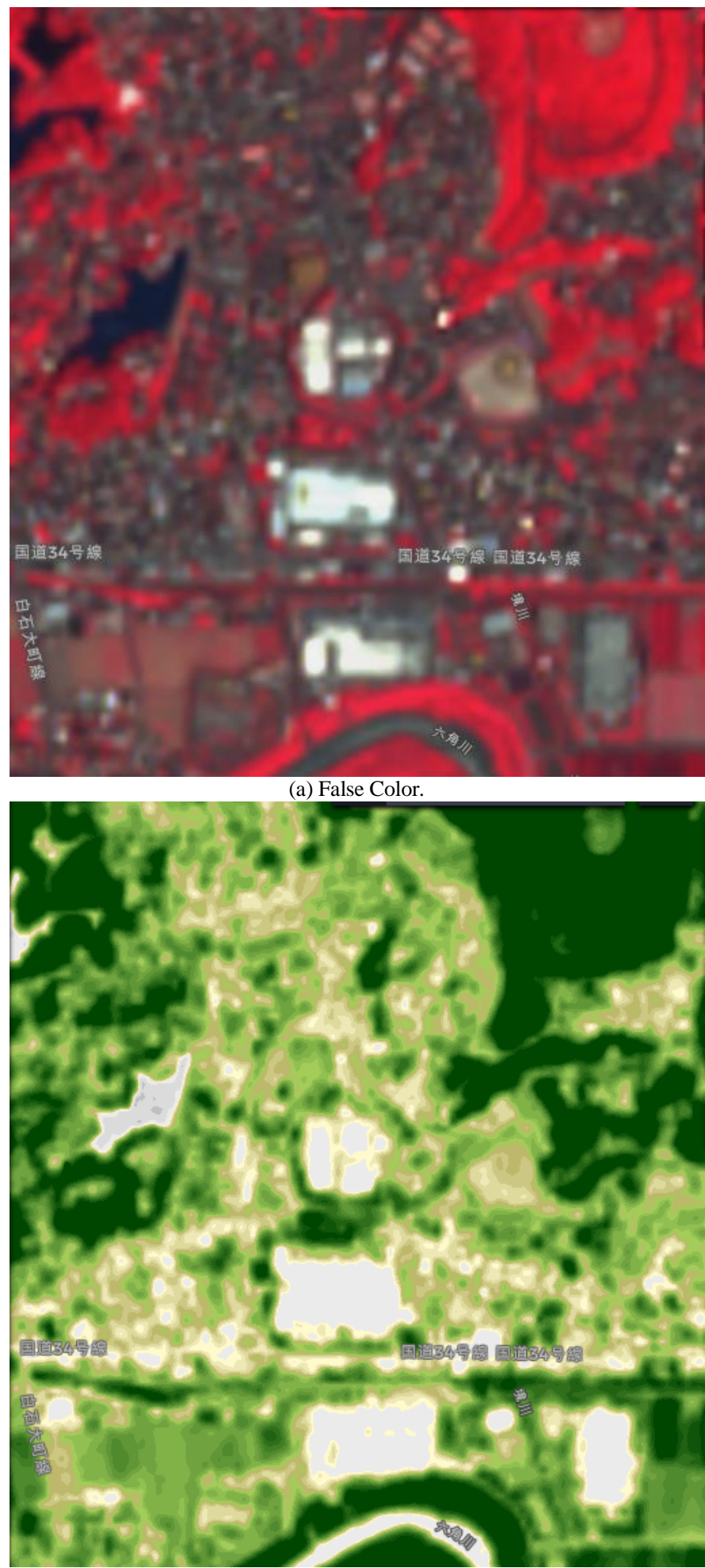

(b) NDVI. 


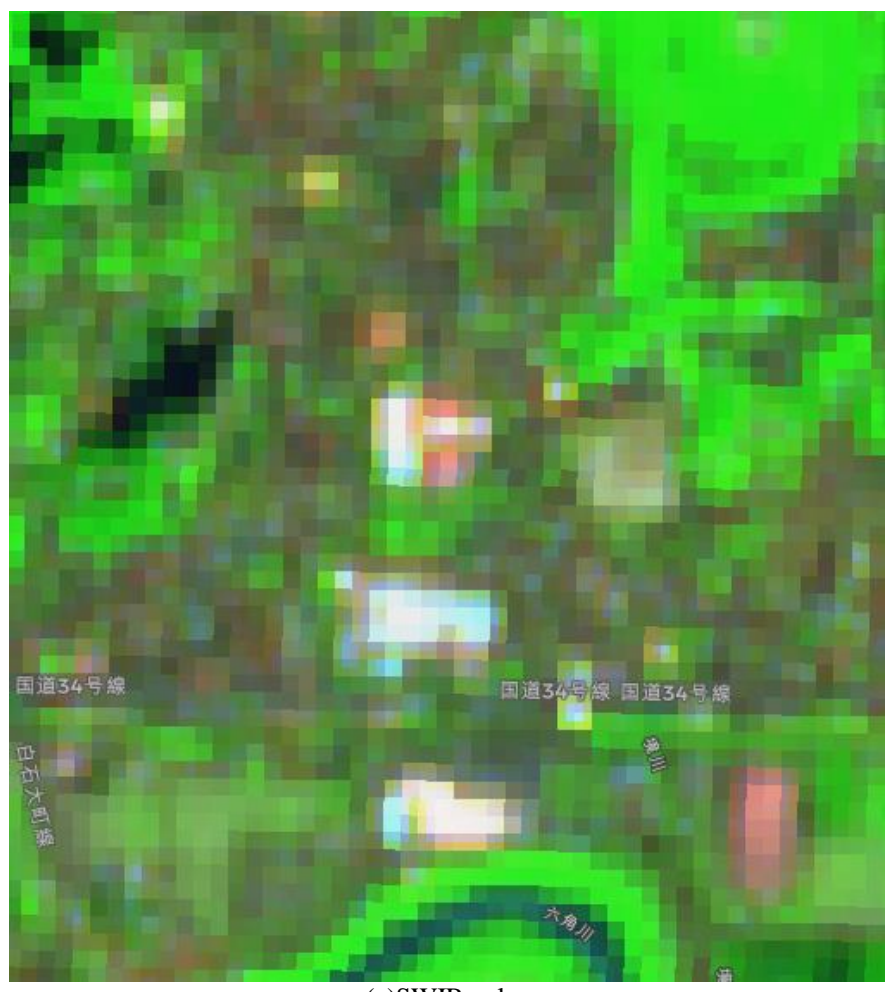

(c)SWIR color

Fig. 9. Sentinel-2 Data Derived False Color Image which is Acquired at 02:08 on August 132019 and NDVI as well as SWIR Color Composite Image.

In the figure of NDVI, color scale is as shown in Fig. 10.

On the other hand, Sentinel-2 data derived false color image which is acquired at 02:08 on September 92019 is shown in Fig. 9(a) while NDVI is shown in Fig. 9(b). Also, Fig. 9(c) shows SWIR color composite image. Due to heavy rain condition, it was not acquired a good Sentinel-2 data on the following dates, August 15, 18, 20, 23, 25, 28, 30, September 2, 4, and 72019.

Because of poor spatial resolution of optical sensor, it is not clear the collapsed area (it has to be situated at the top right corner). Meanwhile, it can be detect the oil spill disaster at the bottom left corner of the false color, NDVI, and SWIR color composite imagery data through a comparison between Fig. 9 and Fig. 11 (just before and after the disaster). Due to the oil spill, surface vegetation is covered with oil so that the surface reflectance and NDVI are decreased.

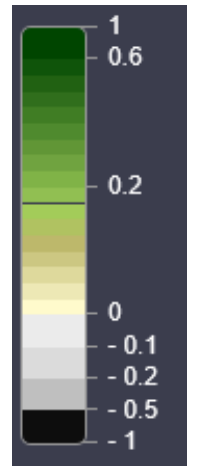

Fig. 10. NDVI Color Scale.
In these figure, the oil spill areas are situated at the bottom left corner while the collapsed area is situated at the top right corner, respectively. Spatial resolution of visible wavelength channels $(10 \mathrm{~m})$ is different from shortwave infrared wavelength channels $(20 \mathrm{~m})$. In particular for collapsed area is just $20 \mathrm{~m}$ by $50 \mathrm{~m}$ so that it is not easy to recognize the location of collapsed area in the SWIR image while it can be found the collapsed area in the visible wavelength channels of false colored images. On the other hand, oil spill areas are identified at the bottom left corner in both visible and SWIR images.
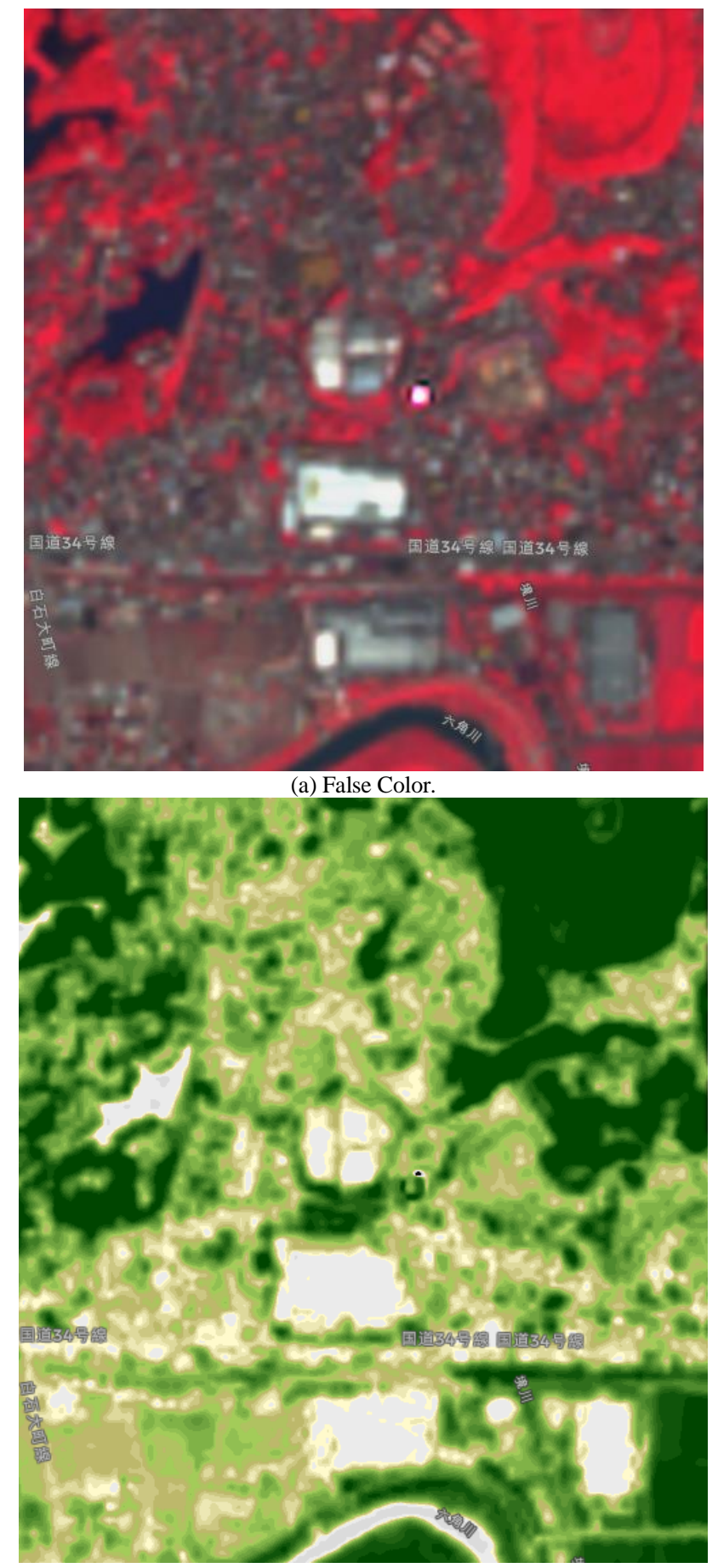

(b) NDVI. 


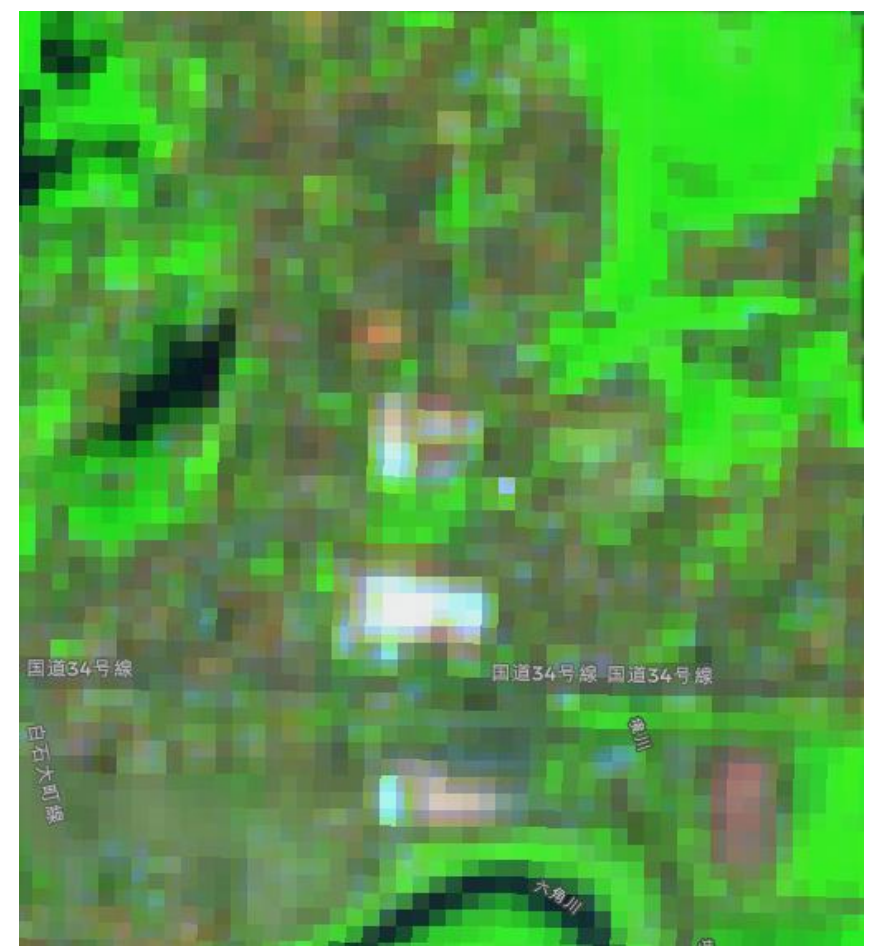

(c) SWIR

Fig. 11. Sentinel-2 Data Derived False Color Image which is Acquired at 02:08 on September 92019 and NDVI as well as SWIR Color Composite Image.

\section{CONCLUSION}

Flooding and oil spill disaster relief using Sentinel of remote sensing satellite data is conducted. Kyushu, Japan had severe heavy rain during from 26 August to 30 August 2019. Optical sensor and Synthetic Aperture Radar: SAR onboard remote sensing satellite is used for disaster relief. NDVI and SWIR data derived from the Sentinel data are used for disaster relief. Merits and demerits of the optical sensor and SAR instrument are compared from the disaster relief of point of view.

Through experiments, it can be detect the oil spill disaster at the bottom left corner of the false color, NDVI, and SWIR color composite imagery data through a comparison between Fig. 9 and Fig. 11 (just before and after the disaster). Due to the oil spill, surface vegetation is covered with oil so that the surface reflectance and NDVI are decreased. Also, it is found that both of oil spill and collapsed disaster areas are detected through a comparison between SAR data which are acquired just before and after the disaster even if the weather condition.is not good and in the night time and day time.

\section{FUtURE RESEARCH WORKS}

Further experimental studies are required for the validation of the proposed method. Also, applicability of the proposed method has to be confirmed through further experiments.

\section{ACKNOWLEDGMENT}

The author would like to thank Professor Dr. Hiroshi Okumura for his valuable discussions.

\section{REFERENCES}

[1] Kohei Arai, Method for estimation of damage grade and damaged paddy field areas sue to salt containing sea breeze with typhoon using remote sensing imagery data, International Journal of Applied Science, 2, 3, 8492, 2011.

[2] Kohei Arai, Back-up communication routing through Internet satellite WINDS for transmitting of disaster relief data, International Journal of Advanced Computer Science and Applications, 2, 9, 21-26, 2011.

[3] 28. Kohei Arai, Tri Harsono, Achmad Basuki, Cellular automata for traffic modeling and simulation in a situation of evacuation from disaster areas, Cellular Automata-Simplicity Behind Complexity, Edit. Aiejandro Salcido, ISDN:978-953-307-230-2, InTech Publishing Co.Ltd., 193-218, 2011.

[4] 83. Kohei Arai, Disaster Monitoring from Space (Remote Sensing Satellites), Research Note for Natural Disaster, No.23, pp.29-34, Mar. 1999.

[5] Kohei Arai, Tri Harsono, Achmad Basuki, Micro traffic simulation with unpredictable disturbance based on Monte Carlo simulation : effectiveness of the proposed agent cars of Sidoarjo hot mudflow disaster, Journal of Emitter, 1, 1, 1-10, 2010

[6] Achmad Basuki, Tri Harsono and Kohei Arai, Probabilistic cellular automata based approach for prediction of hot mudflow disaster area and volume, 1, 1, 11-20, 2010.

[7] Achmad Basuki and Kohei Arai, Two dimensional CA approach for disaster spreading, Innovation Online (INOVASI), 18,12,19-26, 2010.

[8] Kohei Arai, Tri Harsono, Achmad Basuki, Micro traffic simulation with unpredictable disturbance based on Monte Carlo simulation and effectiveness of the proposed agent cars of Sidoarjo hot mudflow disaster, Journal of EMITTER, 1, 1, 10-19, 2010.

[9] Achmad Basuki, Tri Harsono, Kohei Arai, Probabilistic cellular automata based approach for prediction of hot mudflow disaster area and volume, Journal of EMITTER, 1, 1, 1-9, 2010.

[10] Kohei Arai, Achmad Basuki, New Approach of Prediction of Sidoarjo Hot Mudflow Disaster Area Based on Probabilistic Cellular Automata, Geoinformatica - An International Journal (GIIJ), 1, 1, 1-11, 2011.

[11] Kohei Arai, Tri Harsono, Achmad Basuki, Cellular automata for traffic modeling and simulation in a situation of evacuation from disaster areas -Cellular Automata Simplicity behind Complexity-, Edit. Aiejandro Salcido, ISBN:978-953-307-230-2, InTech Pub. 193-218, 2011.

[12] Kohei Arai, Sensor network for landslide monitoring with laser ranging system avoiding rainfall influence on laser ranging by means of time diversity and satellite imagery data based landslide disaster relief, International Journal of Applied Sciences, 3, 1, 1-12, 2012.

[13] Kohei Arai, T.X.Sang, N.T.Uyen, Task allocation model for rescue disable persons in disaster area with help of volunteers, International Journal of Advanced Computer Science and Applications, 3, 7, 96-101, 2012.

[14] T.Harsono, Kohei Arai, Deceleration in the evacuation from disaster area, Journal of Electronics, Mechanics \& Robotics, Informatics \& Computer, Telecommunications (EMITTER), 2, 2, 203-210, 2012.

[15] Kohei Arai, Cell based GIS as cellular automata for disaster spreading predictions and required data systems, Advanced Publication, Data Science Journal, Vol.12, WDS 154-158, 2013.

[16] Kohei Arai, Visualization of 5D assimilation data for meteorological forecasting and its related disaster mitigation utilizing VIS5D of software tool, International Journal of Advanced Research in Artificial Intelligence, 2, 9, 24-29, 2013.

[17] Kohei Arai, Vital sign and location/attitude monitoring with sensor networks for the proposed rescue system for disabled and elderly persons who need a help in evacuation from disaster areas, International Journal of Advanced Research in Artificial Intelligence, 3, 1, 24-33, 2014.

[18] Kohei Arai, Method and system for human action detection with acceleration sensors for the proposed rescue system for disabled and elderly persons who need a help in evacuation from disaster areas, International Journal of Advanced Research in Artificial Intelligence, 3, $1,34-40,2014$ 
[19] Kohei Arai, Vital sign and location/attitude monitoring with sensor networks for the proposed rescue system for disabled and elderly persons who need a help in evacuation from disaster areas, International Journal of Advanced Research in Artificial Intelligence, 3, 1, 24-33, 2014.

[20] Kohei Arai, Method and system for human action detection with acceleration sensors for the proposed rescue system for disabled and elderly persons who need a help in evacuation from disaster areas, International Journal of Advanced Research in Artificial Intelligence, 3, $1,34-40,2014$

\section{AUTHOR's PROFILE}

Kohei Arai, He received BS, MS and PhD degrees in 1972, 1974 and 1982, respectively. He was with The Institute for Industrial Science and Technology of the University of Tokyo from April 1974 to December 1978 also was with National Space Development Agency of Japan from January, 1979 to March, 1990. During from 1985 to 1987, he was with Canada Centre for Remote Sensing as a Post Doctoral Fellow of National Science and Engineering Research Council of Canada. He moved to Saga University as a Professor in Department of Information Science on April 1990. He was a councilor for the Aeronautics and Space related to the Technology Committee of the Ministry of Science and Technology during from 1998 to 2000 . He was a councilor of Saga University for 2002 and 2003. He also was an executive councilor for the Remote Sensing Society of Japan for 2003 to 2005. He is an Adjunct Professor of University of Arizona, USA since 1998. He also is Vice Chairman of the Science Commission "A" of ICSU/COSPAR since 2008 then he is now award committee member of ICSU/COSPAR. He wrote 37 books and published 570 journal papers. He received 30 of awards including ICSU/COSPAR Vikram Sarabhai Medal in 2016, and Science award of Ministry of Mister of Education of Japan in 2015. He is now Editor-in-Chief of IJACSA and IJISA. http://teagis.ip.is.saga-u.ac.jp/index.html. 